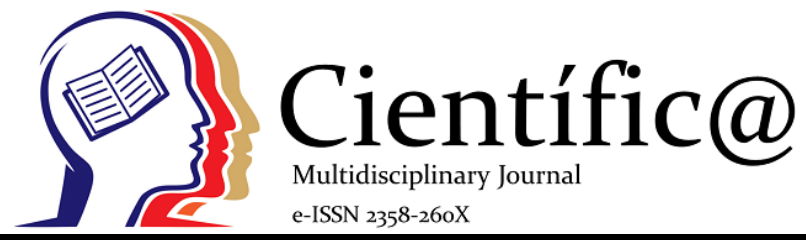

\title{
A Tecnologia Proteômica Como Estratégia Aplicada Ao Diagnóstico Laboratorial
}

\author{
Proteomic Technology As A Strategy Applied To Laboratory Diagnosis \\ Bhruna Kamilla Dos Santos ${ }^{1}$; Amanda Fernandes Costa ${ }^{2}$; Benedito R. Da Silva Neto ${ }^{3}$ \\ ${ }^{1}$ Especialista em Medicina Genômica. Especialista em Biotecnologia e Inovações na Saúde. Pelo Instituto Educacional Santa \\ Catarina Faculdade Jangada. Bacharel em Biomedicina pelo Instituto Educacional Santa Catarina Faculdade Guaraí. \\ bhrunakamilla123@hotmail.com \\ ${ }^{2}$ Especialista em Medicina Genômica. Especialista em Biotecnologia e Inovações na Saúde. Pelo Instituto Educacional Santa \\ Catarina Faculdade Jangada. amanda_nx26@hotmail.com \\ ${ }^{3}$ Pós-Doutorando em Genética Molecular com concentração em Proteômica e Bioinformática. Doutorado em Medicina Tropical \\ e Saúde Pública pela Universidade Federal de Goiás. Mestrado em Biologia Celular e Molecular. Tem experiência na área de \\ Microbiologia Genômica, Engenharia Genética e Quimioinformática. Instituto de Patologia Tropical e Saúde Pública - \\ IPTSP/UFGdr.neto@ufg.br
}

\section{Info}

Recebido: $26 / 02 / 2019$

Publicado: $31 / 05 / 2019$

DOI: 10.29247/2358-260X.2019v6i1.p04-15

ISSN: 2358-260X

\section{Palavras-Chave}

proteômica; diagnostico clinico;

espectrometria de massas.

\section{Keywords:}

proteomics; clinical diagnosis; mass spectrometry.

\section{Resumo}

Introdução: A proteômica é o estudo encarregado de descrever e quantificar as proteínas, assim como suas interações, variações populacionais e alterações em resposta a uma modificação patológica ou fisiológica. Objetivo: Avaliar e descrever as inovações promovidas pela proteômica no contexto laboratorial de diagnóstico patológico, contribuindo para o avanço do desenvolvimento científico da pesquisa clínica. Métodos: Quantificação das publicações disponíveis na base de dados Pubmed relacionadas ao termo Proteômic do ano de 2007 a outubro de 2018 e análise dos artigos publicados no ano de 2017 relacionados aos descritores proteômic and clinic diagnostic. Resultados: Nos últimos 12 anos as publicações relacionadas à Proteômica têm tido um crescimento constante. Nas publicações de 2017 onde a proteômica foi relacionada ao diagnóstico clínico,

$48 \%$ das aplicações foi em biomarcadores, $32,53 \%$ dos objetos de pesquisa foram o câncer, $74 \%$ dos ensaios executados foram in vitro, $63,75 \%$ do método foi em identificação de perfil proteômico, $28,6 \%$ da técnica utilizada foi LC-MS-MS. Conclusão: A proteômica é uma área cientifica que tem avançado e se desenvolvido nos últimos anos e pode trazer muitas contribuições para o diagnóstico clínico, contudo sua aplicação ainda é mais voltada a pesquisa científica.

\footnotetext{
Abstract

Introduction: Proteomics is the study in charge of describing and quantifying proteins, as well as their interactions, population variations and changes in response to a pathological or physiological modification. Objective: To evaluate and describe the innovations promoted by proteomics in the laboratory context of pathological diagnosis, contributing to the advancement of the scientific development of clinical research. Methods: Quantification of publications available in the Pubmed database related to the term Proteomic from the year 2007 to October 2018 and analysis of the articles published in the year 2017 related to the descriptors proteômic and clinic diagnostic. Results: In the last 12 years, publications related to Proteomics have been growing steadily. In the 2017 publications where proteomics was related to clinical diagnosis, $48 \%$ of the applications were in biomarkers, $32.53 \%$ of the research objects were cancer, $74 \%$ of the tests performed were in vitro, $63.75 \%$ of the method was in identification of proteomic profile, $28.6 \%$ of the technique used was LC-MS-MS. Conclusion: Proteomics is a scientific area that has advanced and developed in recent years and can bring many contributions to the clinical diagnosis, but its application is still more focused on scientific research.
} 


\section{INTRODUÇÃO}

No final da década de 70 O' Farrel $^{1}$ desenvolveu a inovadora técnica de eletroforese bidimensional (2D) que separa as proteínas utilizando dois parâmetros diferentes, na primeira dimensão por ponto isoelétrico (ponto onde a carga líquida seja igual a zero) e na segunda por peso molecular. Aplicando esta técnica pesquisadores deram início a bases de dados de proteínas, desenvolvendo o que anos depois viria a ser a proteômica. E de acordo com Parker, Warren e Mocanu $^{2}$ e Weber ${ }^{3}$ no ano de 1994 o termo proteoma foi proposto por Marc Wilkins para denominar todo conteúdo de proteínas expressas por um genoma.

Por meio do sequenciamento do genoma de diversos organismos, os cientistas chegaram à conclusão que apenas as sequencias nucleotídicas não seriam suficientes para compreender as funções dos genes de forma plena, pois para alcançar este alvo se faz necessário o estudo completo das proteínas expressas. Devido ao fato do genoma não está diretamente relacionado com a atividade biológica, mas sim as proteínas, pois dentro do processo da elaboração proteica existem modificações que ocorrem após a transcrição da fita de DNA em RNAm e após a tradução do RNAm em peptídeo, e todo este processo determina a função biológica desempenhada pelo produto final da ação gênica, isto é a proteína produzida. Gerando assim, a necessidade do estudo proteômico para compreender plenamente as ações gênicas ${ }^{4}$.

Em contraste com o genoma o proteoma é extremamente dinâmico, variando de acordo com as condições micro e macro ambientais, e por meio de seu estudo é possível determinar: a expressão de um gene; as concentrações proteicas; as modificações pós traducionais; os processos metabólicos regulatórios e/ou sinalizadores relacionados a um estado fisiológico, patológico ou terapêutico e ainda a descoberta de novos alvos terapêuticos e moléculas bioativas. Logo, a proteômica apresenta maior complexidade em relação a genômica, e caracteriza um avanço no estudo de sistemas biológicos ${ }^{5}$.

De acordo com Galdos-Riveros ${ }^{6}$ no início das análises proteômicas o principal objetivo era apenas a identificação em larga escala de todas as proteínas presentes em uma célula ou tecido. Contudo, este proposito foi modificado, sendo direcionado ao estudo das diferentes características funcionais das proteínas, tais como: interações de proteína com proteína; existência de isoformas, isto é, formas distintas de uma proteína que são produzidas a partir de genes diferentes ou por processo alternativo; diferenciação da expressão proteica em estado patológico ou fisiológico; modificações pós-traducionais; atividades e estruturas.

Conforme Barbosa et al. ${ }^{7}$ a proteômica atua descrevendo e quantificando desde o conjunto de proteínas de uma organela até as existentes em um complexo ecossistema, assim como suas interações, variações populacionais e alterações em resposta a uma modificação patológica ou fisiológica em seu meio ambiente. E segundo Emídio et al. ${ }^{8}$ o procedimento aplicado nos ensaios proteômicos baseia-se na utilização conjunta de diferentes 
técnicas, tais como: eletroforese, cromatografia, espectrometria de massas e as ferramentas da bioinformática, desta maneira executasse a separação e identificação proteica.

A proteômica tem crescido e ampliado sua área de atuação, abrangendo a descoberta de novas drogas, terapias e diagnósticos, inovando também na microbiologia e na bioquímica. Assim, a proteômica tornou possível a identificação e caracterização de moléculas endógenas ou exógenas específicas de um determinado estado patológico, denominadas de marcadores biológicos. O que contribui imensamente no diagnóstico precoce, favorecendo também o prognóstico e o tratamento do paciente ${ }^{8}$.

Para proceder com os estudos proteômicos são aplicadas diferentes técnicas laboratoriais tanto in vitro como in silico. Atualmente a principal técnica utilizada na separação de proteínas é a eletroforese em gel bidimensional, que visa à separação das proteínas por ponto isoelétrico e por peso molecular aparente. Ela possui alto poder de resolução e boa reprodutibilidade na separação de soluções complexas de proteína, como as encontradas em extratos de plantas e soro sanguíneo humano. Possibilitando a análise de expressão gênica por meio da comparação dos padrões proteicos em estudo 4 .

Na aplicação da técnica de eletroforese em gel bidimensional a preparação da amostra é vital para que os resultados sejam fidedignos, sendo que as metodologias de extração, precipitação e solubilização variam de acordo com a amostra. Para a análise dos resultados obtidos as ferramentas da bioinformática e as bases de dados virtuais são de grande utilidade sendo, por exemplo, aplicadas na comparação entre amostras saudáveis e enfermas evidenciando assim características de interesse, tais como: presença, ausência ou intensidade de proteínas específicas que podem ser utilizadas como marcadores biológicos para um determinado quadro patológico ou ainda como acompanhamento terapêutico. Porém, a determinação da identidade das proteínas após sua separação em spots de proteínas por eletroforese bidimensional, inicialmente era dificultada pelos métodos analíticos aplicados, pois estes eram lentos e pouco sensíveis. Contudo, em 1990 a espectrometria de massas emergiu como um poderoso método analítico que eliminou a maioria das limitações encontradas nas análises proteômicas ${ }^{9}$.

A técnica da espectrometria de massas baseia-se no fato de que cada composto possui uma fragmentação única, um padrão de espectro de massa específico. Consistindo basicamente, na ionização de um composto e na avaliação da razão massa/carga $(\mathrm{m} / \mathrm{z})$ dos íons, em fase gasosa. 0 equipamento utilizado compreende uma fonte de ionização, um ou mais analisadores de massas, um detector e um sistema de aquisição de dados $^{7}$.

$\mathrm{Na}$ espectrometria de massas a amostra proteica passa pela ionização seja por electrospray (ESI) ou por dessorção a laser assistida por matriz (MALDI), em seguida um analisador ou múltiplos analisadores irão medir a massa dos íons, os mais utilizados são o analisador de massa quadrupolo e/ou o de tempo de voo (ToF), e podem ser 
empregados em conjunto como instrumentos espectrométricos de massa em tandem QToF. As massas obtidas formam uma espécie de impressão digital (fingerprinting) da proteína. Softwares especiais permitem comparar o fingerprinting da proteína com os presentes nos bancos de dados, identificando a mesma se estiver presente no banco $^{10}$.

Por meio deste avanço, unido ao sequenciamento do genoma humano completo e disponibilizado em bases de dados públicas, teve início um novo tempo. Atualmente, o termo proteômica abrange mais do que uma análise funcional dos produtos dos genes ou genômica funcional, inclui também os estudos em larga escala da identificação e localização proteica. Já a analise estrutural de proteínas é estudada na genômica estrutural. Vale destacar, que o controle da expressão gênica inicia com a transcrição do RNAm, e segue com as modificações pós-traducionais como glicosilação, fosforilação, acetilação, hidroxilação, carboxilação, ubiquitinação, entre outras, as quais modificam as atividades proteicas. Com base no exposto, a análise proteômica é atualmente o meio mais eficiente e aplicado no estudo funcional dos genes e genomas de organismos complexos ${ }^{6}$.

O proteoma de um indivíduo é uma entidade dinâmica que se altera constantemente em resposta aos diversos processos celulares, inclusive os que ocorrem mediante uma enfermidade ou um tratamento medicamentoso. No âmbito da medicina personalizada, através das informações obtidas pela descrição das proteínas encontradas em uma dada patologia é possível não apenas estabelecer um diagnóstico mais rápido e seguro, mas também determinar o melhor tratamento a ser prescrito e a eficácia do mesmo. Em vista disso, com os avanços nas técnicas de proteômica e com os sistemas de processamento de dados, desenvolvidos pela bioinformática, a proteômica em conjunto com a farmacogenômica nos conduzira a uma nova forma de diagnóstico e tratamento ${ }^{3,11}$.

Ressalto que o diagnóstico laboratorial possui extrema importância na determinação da patologia e do tratamento mais seguro, eficaz e recomendado a ser procedido pela equipe medica. De acordo com tudo que já foi exposto é evidente que os estudos e avanços na área proteômica podem contribuir nos avanços diagnósticos. E assim como afirma Emídio, et $a l^{8}$ o estudo do proteoma, bem como a elucidação da função das proteínas no contexto em que são expressas são de grande relevância para o prognóstico e terapia de doenças.

Embasados neste conceito surge à problemática desta revisão: quais inovações a proteômica tem proporcionado no diagnostico laboratorial? Pois, diante da grande importância do diagnóstico precoce e preciso, e do potencial da proteômica para a descoberta e desenvolvimento de novos biomarcadores e métodos diagnósticos, surge à necessidade de analisar os avanços que a proteômica tem estabelecido no campo do diagnóstico laboratorial, justificando assim este trabalho.

Portanto, este estudo tem por objetivo avaliar e descrever as inovações promovidas pela proteômica no contexto laboratorial de diagnóstico 
patológico, corroborando para o avanço do desenvolvimento científico da pesquisa clínica.

\section{MATERIAL E MÉTODOS}

Para a fundamentação teórica da introdução e da discussão foi realizada uma revisão bibliográfica baseada nos artigos científicos disponíveis na base de dados Pubmed e em literatura especializada.

Para o levantamento de dados sobre os avanços da proteômica aplicada ao diagnostico laboratorial foram analisados artigos publicados na base de dados Pubmed de janeiro a dezembro de 2017 usando os descritores: proteômic and clinic diagnostic, categorizando as informações de interesse dos artigos encontrados, foram estes: autor (es), palavras-chave, técnica, método, objeto, aplicação, e execução ou não de ensaio clínico; na ausência de palavras-chave o título do artigo foi utilizado em seu lugar. Posteriormente com os dados de interesse foram geradas figuras, por meio do programa Excel. A pesquisa foi executada de maio a setembro de 2018 e as informações obtidas ficam limitadas a atualização da base de dados Pubmed no período da execução da pesquisa.

Foi também categorizado o total de publicações referentes ao termo Proteômic, na base de dados Pubmed, utilizando o programa Excel, restringido do primeiro mês do ano de 2007 ao décimo mês do ano de 2018, extraindo o número total de artigos relacionados ao termo em pesquisa a cada ano filtrado $(2007,2008,2009,2010,2011$,
2012, 2013, 2014, 2015, 2016, 2017, 2018), com o resultado foi executada análise estatística utilizando o programa Bioestat 5.0 (AYRES $^{12}, 2007$ ), o levantamento destes dados foi realizado em outubro de 2018, por consequência, as informações obtidas ficam limitadas a atualização da base de dados Pubmed no período da execução da pesquisa.

\section{RESULTADOS E DISCUSSÃO}

O estudo proteômico é uma ferramenta inovadora, pois proporciona o conhecimento qualitativo, quantitativo e estrutural das proteínas, e estas possuem muitas funções na fisiologia celular, além de integrarem relevantes alvos farmacológicos e biomarcadores patológicos. Por meio da proteômica é possível identificar os peptídeos expressos no momento da análise, quantificá-los e averiguar as modificações pós traducionais, deixando evidente a importância destas pesquisas ${ }^{8}$.

Ao longo dos últimos anos a quantidade de publicações relacionadas à proteômica tem aumentado gradativamente, como foi possível demonstrar por meio da quantificação dos artigos publicados no Pubmed referentes ao termo Proteômic do ano de 2007 a outubro de 2018. Em nossos resultados em 2007 ocorreram 5,45\% das publicações, em 2008 foram 5,95\%, em 2009 foram 6,57\%, no ano de 2010 foram 7,2\%, em 2011 foram 7,88\%, em 2012 foram 8,35\%, em 2013 foram 8,44\%, em 2014 foram 9,58\%, em 2015 foram 10,19\%, em 2016 foram 10,82\%, em 2017 foram 10,57\% e em 2018 até o mês de outubro foram 9\%. Como fica demonstrado na Figura 1. 


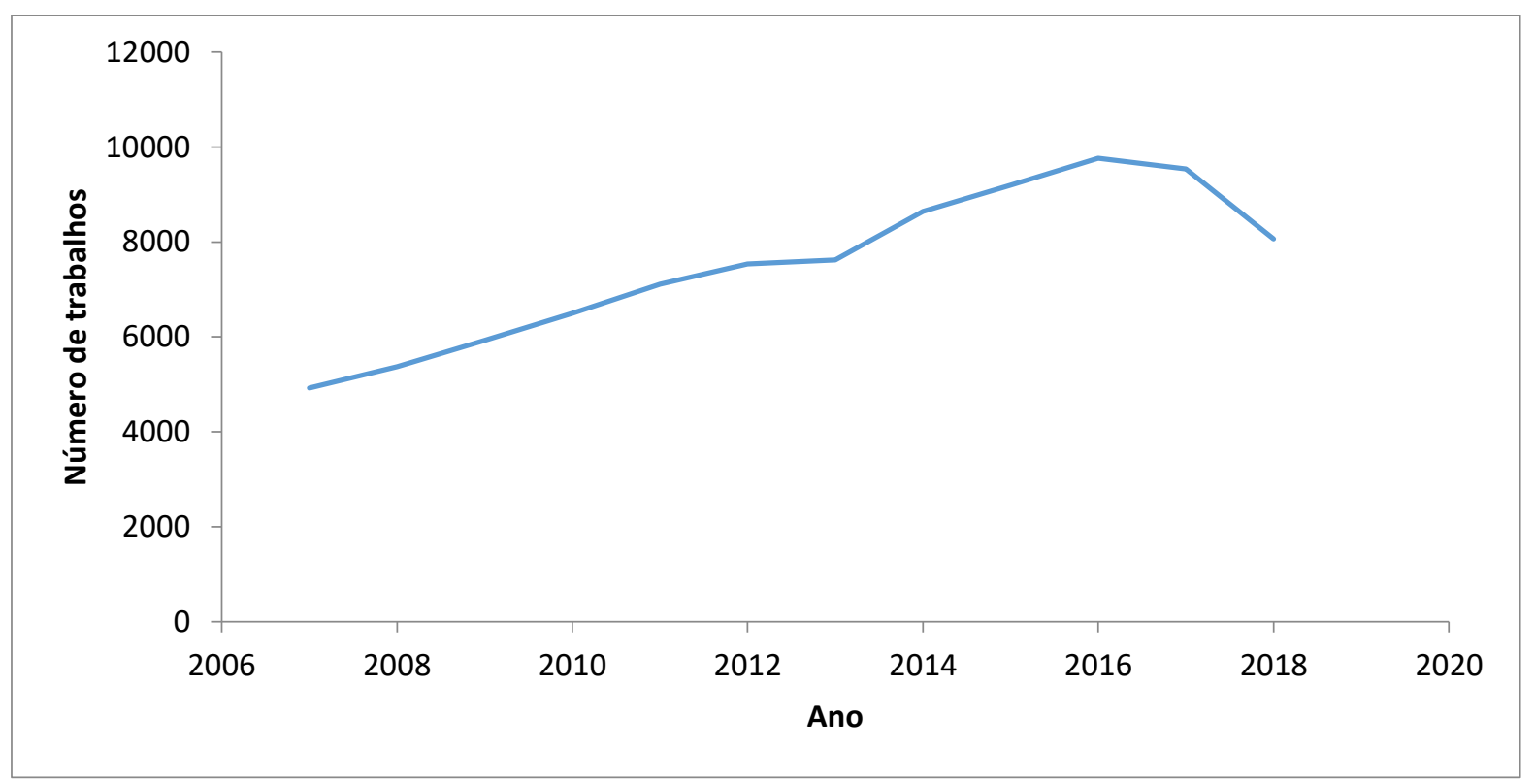

Figura 1 - Incidência do termo proteômic nos artigos publicados no Pubmed do período de janeiro de 2007 a outubro de 2018. Os Dados foram obtidos no site: https://www.ncbi.nlm.nih.gov/pubmed/.

De acordo com o levantamento feito na base de dados Pubmed foram encontrados e analisados noventa mil duzentos e doze (90212) artigos publicados no período de janeiro de 2007 a outubro de 2018. Percebe-se que o número de trabalhos aumentou de forma significativa ao longo dos anos pesquisados $(r=0,931 ; p=0,0001)$, sendo que o ano de 2007 apresentou o menor número de artigos quatro mil novecentos e vinte e quatro (4924) e o ano de 2017 a maior quantidade de trabalhos nove mil setecentos e sessenta e seis (9766) com média de sete mil quinhentos e dezessete (7517) artigos por ano. De acordo com Barbosa et al., (2012) nos últimos anos, muitas questões biológicas importantes têm sido respondidas pela proteômica e centenas de biomarcadores candidatos foram descobertos, logo, o desenvolvimento cientifico desta área vem se estabelecendo

O declínio observado nos dados de 2018 e justificável por apenas dez meses terem sido analisados, ao findar do ano é muito provável que as publicações continuaram a seguir o crescimento visto nos demais anos. Contudo fica evidente a contínua elevação no número de publicações relacionadas à Proteômica e os resultados obtidos demonstram que essa é uma área em constante expansão.

Entretanto, um estudo voltado a proteômica aplicada ao diagnóstico clínico faz-se necessário por contribuir na avaliação e descrição do desenvolvimento desta área, buscando assim, beneficiar o diagnóstico, tratamento e prognóstico dos pacientes.

Portanto, essa pesquisa realizou um levantamento de dados sobre os avanços da proteômica aplicada ao diagnostico laboratorial, onde foram analisados os artigos da base de dados Pubmed publicados no ano de 2017 relacionados aos descritores: Proteômic and clinic diagnostic. E foram encontrados cento e dois (102) artigos, porém, 
foram excluídos do estudo vinte e cinco (25) artigos por não abordarem a proteômica aplicada ao diagnóstico clínico. De modo que os setenta e oito (78) artigos que abordaram o tema em estudo foram inseridos nas análises e categorizados em: autor (es), palavras-chave, técnica, método, objeto, aplicação e execução ou não de ensaio clínico. Levando a construção de uma tabela que está disponível como material suplementar no anexo II. Foram construídas algumas figuras, utilizando o programa Excel, buscando apresentar melhor os resultados obtidos nesta pesquisa.
Os estudos com biomarcadores tem sido relevante nesta área da ciência como foi possível demonstrar nas aplicações dos artigos avaliados, onde estes foram agrupados em seis diferentes temas de aplicação: microrganismos com 3,7\% dos artigos; alvos terapêuticos com 3,7\% dos artigos; fisiopatologia com 9,87\% dos artigos; procedimento diagnóstico com 13,58\% dos artigos; informações técnicas com 20,98\% dos artigos; e biomarcadores com $48 \%$ dos artigos. Como fica demonstrado na figura abaixo:

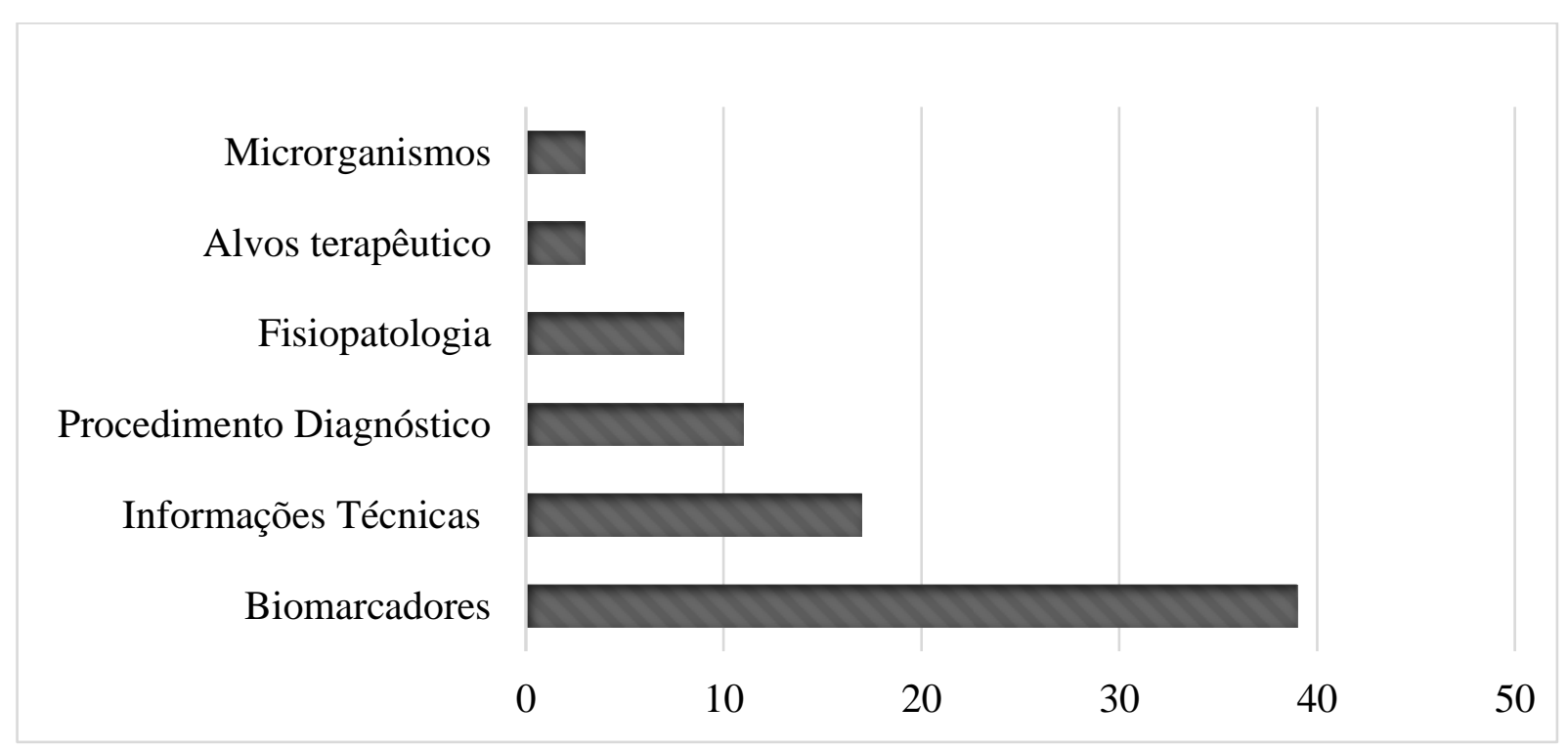

Figura 2 - Aplicações dos estudos analisados publicados no Pubmed no ano de 2017, relacionados ao termo proteômic and clinic diagnostic. Os Dados foram obtidos no site: https://www.ncbi.nlm.nih.gov/pubmed/ .

Na soma das aplicações foram obtidas oitenta e uma (81), apesar de serem analisados 78 artigos, e isto pode ser justificado por três artigos terem mais de uma aplicação. De acordo com os dados obtidos, fica constatado que a grande maioria das aplicações dos artigos foi em Biomarcadores, deixando evidente o crescimento de pesquisas nesta área. Os estudos buscavam a descoberta, validação e revisão dos Biomarcadores, e boa parte destes era aplicada ao diagnóstico e alguns ao prognóstico. Nas pesquisas de informações técnicas dentre os trabalhos encontrados $24 \%$ abordam o câncer, $12 \%$ as doenças cardiovasculares, $12 \%$ as lesões renais e $12 \%$ o sêmen, dentre outros objetos, ressaltando o empenho científico aos estudos cancerígenos.

No desenvolvimento deste estudo também foram classificados e quantificados os objetos de 
pesquisa dos artigos em análise, pois é importante ter conhecimento do foco de aplicações das produções científicas em questão. Conseguinte, foi realizada a classificação dos objetos em doze (12) grupos, e outros catorze (14) objetos serão apenas relatados, pois não se adequaram ao agrupamento. Os grupos foram: câncer com 32,53\% dos artigos; doença renal com 8,43\% dos artigos; doença cardiovascular com 7,22\% dos artigos; doença autoimune com 7,22\% dos artigos; sêmen com 4,8\% dos artigos; microrganismos com 4,8\% dos artigos; doenças neurológicas com 4,8\% dos artigos; asma com 3,6\% dos artigos; distúrbio psíquico com 2,4\% dos artigos; síndrome do olho seco com 2,4\% dos artigos; síndrome da dor regional complexa (SDRC) com 2,4\% dos artigos; proteoma sérico com 2,4\% dos artigos. Os objetos que não entraram nos grupos, foram: pleurisia tuberculosa; células $\beta$; préeclâmpsia; imunoterapia; glaucoma; doença de Crohn; células-tronco; Parthenium hysterophorus (erva daninha); alterações genéticas de ARID1B; secretoma de células Jurkat; Gengiva; tireotoxicose; Obesidade. Estes objetos não agrupados foram utilizados apenas uma vez. Na soma dos objetos de pesquisa foram obtidos oitenta e três (83), apesar de serem analisados 78 artigos, e isto pode ser justificado por alguns artigos terem mais de um objeto de pesquisa. Na figura 3 observamos os grupos de objetos classificados:

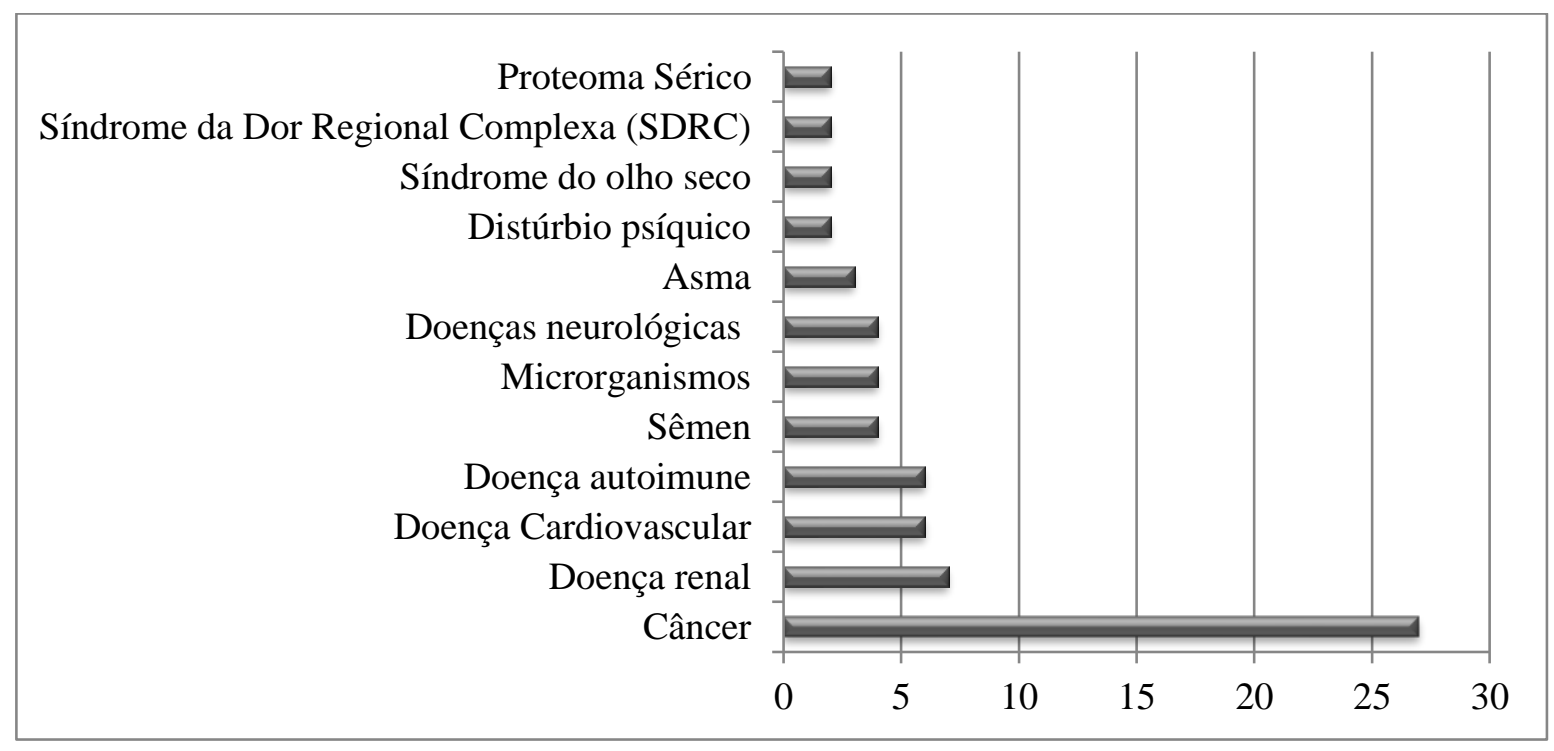

Figura 3 - Quantificação e agrupamento dos objetos de pesquisa dos estudos analisados publicados no Pubmed no ano de 2017, relacionados ao termo proteômic and clinic diagnostic. Os Dados foram obtidos no site: https://www.ncbi.nlm.nih.gov/pubmed/.

Estes resultados demonstram que o objeto de pesquisa dos artigos com maior destaque é o câncer, ficando evidente que este alvo de estudos está em constante crescimento. As pesquisas que utilizaram este objeto abordaram diferentes tipos desta enfermidade, tais como: câncer de pulmão; câncer endometrial; adenocarcinoma ductal pancreático; colangiocarcinoma; câncer de próstata; carcinoma fibrolamelar; carcinoma de células renais humanas; metástases hepáticas colorretais (MLCC); 
carcinoma ductal invasivo (IDC); carcinoma hepatocelular; câncer de mama; dentre outros tipos cancerígenos. Logo, ganha destaque os diferentes tecidos que podem ser atingidos por essa enfermidade, assim como, a ação de suas diferentes formas e a busca dos estudos em auxiliar no tratamento. De acordo com Zhao, et $a^{13}{ }^{13}$, os atuais avanços dos conhecimentos relacionados as bases genômicas e as ações oncogênicas nos variados tipos cancerígenos, demonstram a importância do diagnóstico precoce e correto para o melhor desempenho do tratamento e a escolha adequada do mesmo.
Os experimentos realizados in vitro, in vivo e in silico são muito importantes para o progresso de uma pesquisa, pois através destes métodos é possível realizar testes aplicando técnicas bioquímicas, genéticas ou imunológicas ou ainda realizar ensaios em cobaias animais e também testes preditivos computacionais. Gerando a possibilidade de comprovação ou não da tese de uma pesquisa e enriquecendo o conhecimento científico. Portanto, na pesquisa executada quantificamos os artigos que executaram ensaio in vitro $74 \%$, ensaio in vivo $4 \%$, ensaios in silico 3,8\% e os que não realizaram ensaios $16,6 \%$ estes executaram apenas a revisão bibliográfica, como observado na figura 4 :

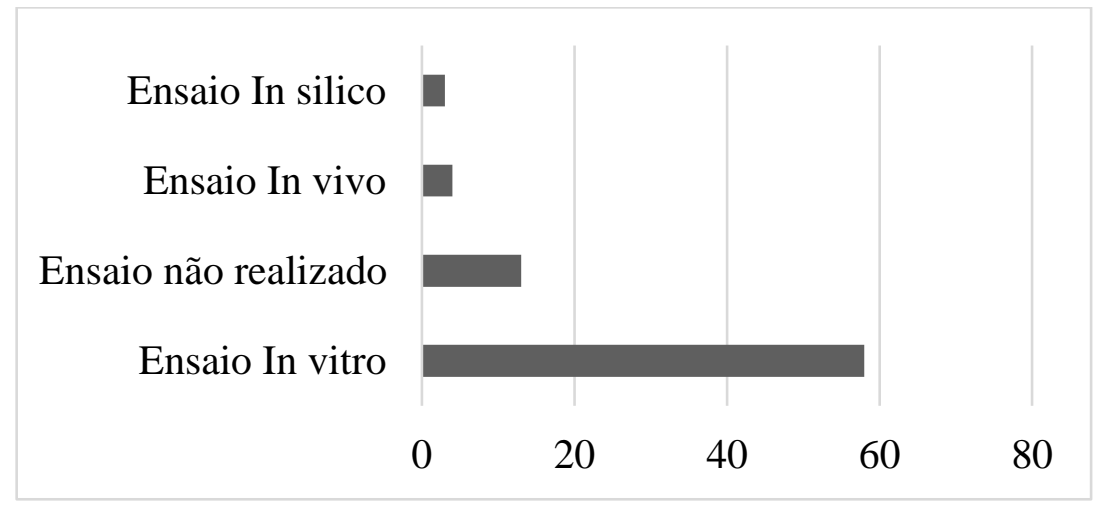

Figura 4 - Classificação e quantificação de artigos quanto a execução de ensaios publicados no Pubmed no ano de 2017, relacionados ao termo proteômic and clinic diagnostic. Os Dados foram obtidos no site: https://www.ncbi.nlm.nih.gov/pubmed/.

Por meio desta análise, podemos observar que a maior parte das publicações relacionadas a proteômica nas análises clínicas incluem ensaios in vitro, o que é muito bom para a melhor compreensão das hipóteses levantadas e para o desenvolvimento e aplicação dos estudos realizados. Também obteve destaque a não aplicação de testes onde a única técnica utilizada para o desenvolvimento destes estudos foi a revisão de literatura, que apesar de não ser suficiente para a comprovação de teorias, tem seu valor por produzir reflexões e revisões que proporciona um importante embasamento teórico que é o início de toda produção cientifica, contribuindo assim, no avanço do conhecimento.

Contudo, no caso do ensaio in silico os dados obtidos refletem apenas a quantidade de artigos que aplicaram estritamente essa técnica preditiva, não representando a grande importância e 
utilização deste experimento nas pesquisas atualmente. Pois, este ensaio aplica simulação computacional o que gera economia, melhor aproveitamento do tempo e torna possível a seleção das melhores possibilidades, o que permite levar para a bancada de ensaio in vitro ou in vivo um teste com probabilidades mais favoráveis. Na proteômica essa técnica está intrínseca, pois faz parte da análise dos dados produzidos, com isso não ganha exclusividade nas descrições metodológicas ainda que seja fundamental no estudo das informações obtidas, pois estas necessitam passar por análises computacionais. Com isso subentende-se que os estudos que aplicaram teste in vitro utilizando da proteômica consequentemente realizam o ensaio in silico também.

Em relação as metodologias utilizadas estas foram das mais variadas, contudo três se sobressaíram as demais, a primeira foi a identificação de perfil proteômico com $63,75 \%$ dos artigos, a segunda com $18,75 \%$ dos trabalhos foi a revisão e a terceira com $3,75 \%$ das publicações foi o método preditivo. Os demais métodos utilizados foram: Microarrays de proteínas; identificação do Proteoma nuclear; comparação de dados proteômicos; aplicação do índice de resposta precoce (ERI); imunoensaio proteômico multiplex; análise morfológica; imunoproteômica; estimulação LIPUS; avaliar capacidade de isolamento; identificação de fenótipo molecular e clínico; modelo animal para imagens de nichos pré-metastáticos distais.

O destaque desta análise é para o método de identificação de perfil proteômico, que foi muito aplicado na descoberta de novos biomarcadores, estando em concordância com os dados da análise de aplicações das pesquisas onde biomarcadores estava em $48 \%$ dos estudos. E através do perfil proteômico diversos caminhos se abrem para grandes descobertas, como já foi comentado anteriormente, as análises computacionais integram o estudo proteômico, deste modo, fica subentendida a participação das análises preditivas dentro este método, deixando claro que a quantidade de 3,75\% é referente a artigos que utilizaram apenas esse método em suas análises.

A técnica aplicada para o desenvolvimento da metodologia proposta são as mais diversas, para a execução dos testes proteômicos o equipamento principal é o espectrômetro de massas, onde o teste é executado, ele pode ser composto por diferentes executores de ionização e detecção, o que produz deferentes formas de análise. Neste estudo, as técnicas aplicadas nas pesquisas foram classificadas e quantificadas em trinta e nove grupos, onde as 17 que se destacaram das demais foram: LC-MS-MS com $28,6 \%$; imunoensaios com $11,7 \%$; 2 D com $7,3 \%$; MALDI-TOF-MS, Microarrays, Revisão bibliográfica e Microscopia eletrônica com 3,6\%; RT PCR com 2,9\%; LC-MRM-MS, LC-ESI-MS-MS e Estudo in silico com 2,2\%; ELISA, MALDI-MSI, MS quantitativa livre, Microdissecção a laser, CE-MS e Hibridação in situ fluorescente com 1,4\%. Estas técnicas irão compor a figura 6 , porém as técnicas com apenas $0,7 \%$ não farão parte da figura, esta são: miARN; ressonância de plasmon de superfície; ultrassonografia carotídea; Tags isobáricas; microdissecção por captura a laser; matriz de proteína programável por 
ácido nucléico [NAPPA]; informática de sistemas; rastreamento de nano partículas; SISMuc em cultura estática e dinâmica; ultrassom pulsado de baixa intensidade (LIPUS); espectrofotometria Nanodrop; microscopia de força atômica (AFM); citometria de fluxo em nano escala (NFC); modelo de regressão logística; Gene Chip; marcação de conjugados; MALDI-TOF / TOF; GC-MS; Fingerprinting ADSRRS; biópsia; biolumiscência; SWATH-MS. Como fica demonstrado na figura 6 :

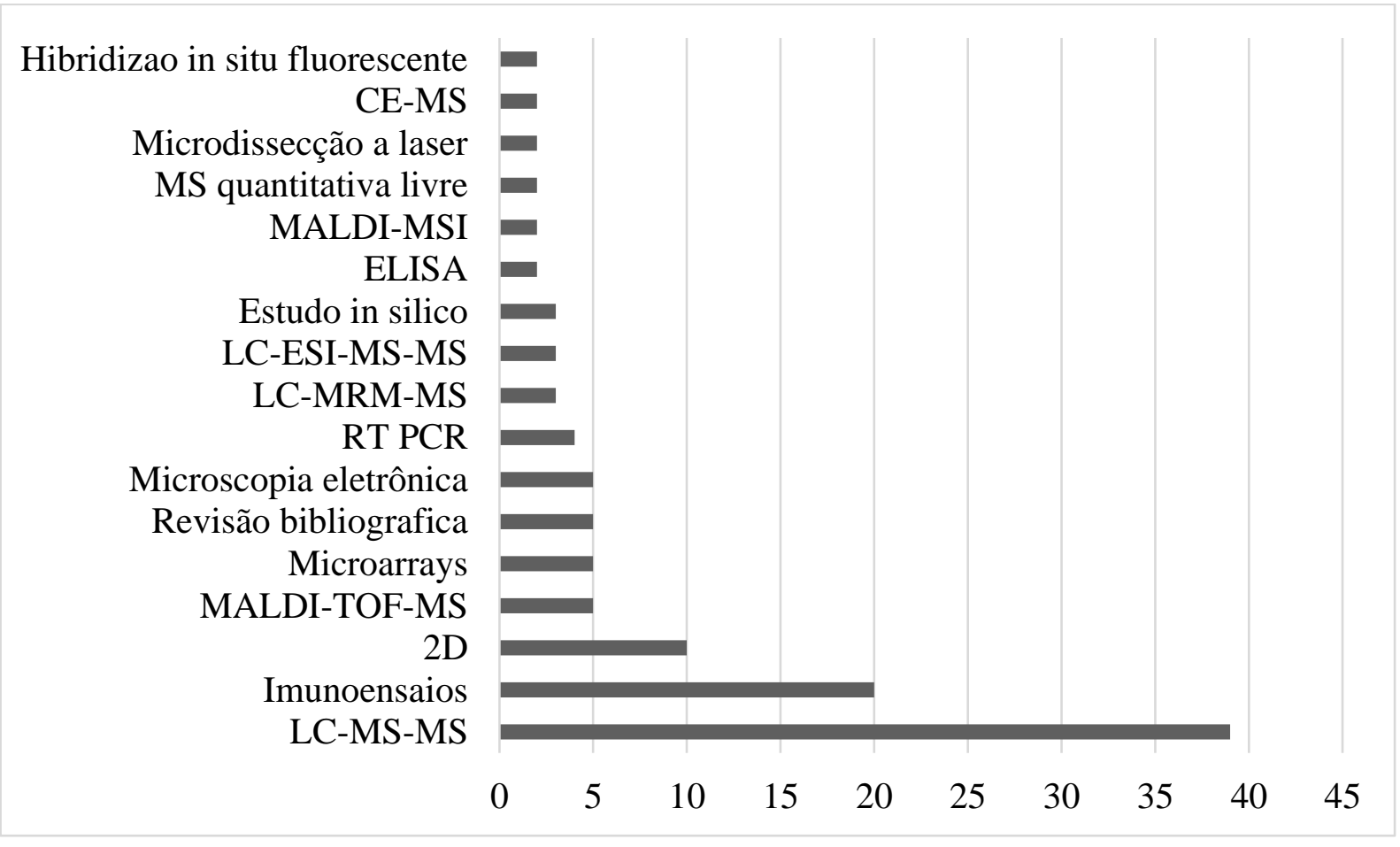

Figura 6 - Técnicas mais utilizadas nos artigos em estudo publicados no Pubmed no ano de 2017, relacionados ao termo proteômic and clinic diagnostic. Os Dados foram obtidos no site: https://www.ncbi.nlm.nih.gov/pubmed/ .

A técnica com maior aplicação nos estudos foi a LC-MS-MS com 28,6\% ela utiliza como preparação da amostra a cromatografia liquida e para realizar o teste dois espectrômetros de massas, buscando atingir resultados mais puros e sensíveis. $A$ segunda técnica mais executada foram os imunoensaios que representam um grupo de diferentes testes imunológicos como: ensaio imunoenzimático, ELISA, imunofluorescência, imuno-histoquímica, entre outros, que por meio de reações imunológicas buscam resultados fidedignos. A eletroforese bidimensional (2D) foi a terceira técnica com maior aplicação, por meio dela as proteínas são segregadas em duas dimensões uma por peso molecular e a outra por ponto isoelétrico, esta técnica é muito aplicada como primeiro meio de preparação da amostra em testes proteômicos.

Deste modo, essa pesquisa fez o levantamento dos dados de maior relevância dos artigos em análise, conduzindo a formação de uma visão das publicações proteômicas aplicada no âmbito laboratorial no ano de 2017.

\section{CONCLUSÃO}

A proteômica tem inovado e avançado rapidamente nos últimos anos, além de estar sendo 
aplicada em diversas áreas do conhecimento. Nos últimos anos, os dados proteômicos tem passado por grande expansão, gerando a necessidade de uma melhor análise dos mesmos, pois apesar de gerados precisam ser trabalhados in silico e levados aos testes laboratoriais e posteriormente aos ensaios clínicos para que possam ser utilizados pela população.

Contudo, dentro das análises clínicas os testes proteômicos ainda não atingiram seu ápice, pois boa parte das pesquisas ainda está em fases iniciais, entretanto é evidente que essa área do conhecimento tem muito para oferecer no desenvolvimento diagnóstico, prognóstico e de tratamento por sua grande sensibilidade e especificidade, no entanto tem tido mais utilização no âmbito das pesquisas cientificas.

Portanto, este estudo teve o objetivo de avaliar e descrever as inovações promovidas pela proteômica no contexto laboratorial de diagnóstico patológico, buscado assim, colaborar para o avanço do desenvolvimento científico da pesquisa clínica.

\section{REFERÊNCIAS}

1. O'FARRELL, P. H. Eletroforese bidimensional de alta resolução de proteínas. J. Biol. Chem. v. 250, n. 10, p. 4007-4021, 1975. Disponível em: < https://www.ncbi.nlm.nih.gov/pmc/articles/PMC2874 754/pdf/nihms201444.pdf >. Acesso em 06 de março de 2018.

2. PARKER, C. E. WARREN, M. R. MOCANU, V. Neuroprotemics. Fronteiras na Neurociência. Universidade da Carolina do Norte. Editor Oscar Alzate. Cap 5. Boca Raton (FL): CRC Press / Taylor \& Francis; 2010. Disponível em: <https://www.ncbi.nlm.nih.gov/books/NBK56018/>. Acesso em 11 de março de 2018.
3. WEBER, S. S. Abordagens proteômicas e suas aplicações no campo da hematologia. Artigo de conclusão do curso de pós-graduação em Hematologia Laboratorial, AC\&T, São José do Rio Preto. 2013. Disponível em: $<$ http://www.ciencianews.com.br/arquivos/ACET/IMA GENS/revista_virtual/hematologia/hemato27.pdf>. Acesso em 11 de março de 2018.

4. GÓES, A. C. S. OLIVEIRA, B. V. X. Projeto genoma humano: um retrato da construção do conhecimento científico sob a ótica da revista Ciência Hoje. Ciênc. Educ., Bauru, v. 20, n. 3, p. 561-577, 2014.

5. CHANDRASEKHAR, K. et al. A short review on proteomics and its applications. International Letters of Natural Sciences Online. Vol. 17, pg 77-84. 2014.

6. GALDOS-RIVEROS, A. C. et al. Proteômica: novas fronteiras na pesquisa clínica. ENCICLOPÉDIA BIOSFERA, Centro Científico Conhecer - Goiânia. V.6, N.11. 2010.

7. BARBOSA, E. B. et al. Proteômica: metodologias e aplicações no estudo de doenças humanas. Rev Assoc Med Bras. V. 58, n. 3, pg: 366-375, 2012.

8. EMIDIO, N. B. et al. Proteômica: uma introdução aos métodos e aplicações. HU Revista, Juiz de Fora, v. 41, n. 3 e 4, p. 101-111, jul./dez. 2015.

9. ROCHA, T. L. et al. Eletroforese em gel bidimensional e análise de proteoma. Comunicado técnico 136. Embrapa. Brasília. 2005.

10. EL-ANEED, A; Cohen A; Banoub, J. Mass spectrometry, review of the basics: electrospray, maldi, and commonly used mass analyzers. Journal Applied Spectroscopy Reviews, v. 44, e. 3, p. 210-230, mar. 2009.

11. MATA, O. M. Farmacogenética, farmacogenómica y proteômica. Monografía XV: Nuevos avances en medicamentos en la medicina personalizada. REAL ACADEMIA NACIONAL DE FARMACIA. 2004. Disponível em: <http://www.analesranf.com/index.php/mono/article/ view/534/552>. Acesso em 02 de setembro de 2017.

12. AYRES, M. et al. Aplicações estatísticas nas áreas das ciências biomédicas. Bio Estat. Belém do Pará, Brasil, 2007.

13. ZHAO, X. et al. Quantitative Proteomic Analysis of Optimal Cutting Temperature (OCT) Embedded Core-Needle Biopsy of Lung Cancer. Journal of The American Society for Mass Spectrometry, v. 28, e. 10, p. 2078-2089, Oct. 2017. 